\title{
Fetal Hydantoin Syndrome: A Case Report
}

\section{Shakya NS ${ }^{1}$, Gurubacharya SM², Aryal DR ${ }^{3}$}

${ }^{1}$ Dr. Needa Shrestha Shakya, MBBS, Medical Officer, ${ }^{2}$ Dr. Simmi Misra Gurubacharya, MBBS, MD, Registrar, ${ }^{3}$ Dr. Dhana Raj Aryal, Consultant Pediatrician and Neonatologist, NICU, Maternity Hospital (Prasuti Griha), Kathmandu, Nepal.

Address for Correspondence: Dr. Needa Shrestha Shakya, E-mail: needash@yahoo.com

\begin{abstract}
A term baby born to an epileptic mother who was treated with Phenytoin until 10weeks of pregnancy was born with multiple congenital anomalies and diagnosed to have Fetal Hydantoin Syndrome. Infants of mothers who have taken hydantoin during pregnancy have been found to have broad multisystem patterns of abnormalities, including mental retardation, craniofacial anomalies, nail and digital hypoplasia and prenatal onset of growth deficiency. The discussion aims to bring to attention the potential hazard of the use of hydantoin drug during reproductive age to all medical practitioners.
\end{abstract}

Key words: Congenital anomalies, epilepsy, fetal hydantoin syndrome, phenytoin.

\section{The Case}

$\mathrm{A}^{\mathrm{t}}$ full term baby (41wks) was born to a $\mathrm{G}_{3} \mathrm{P}_{2} \mathrm{~L}_{1}$ mother with polyhydramnios having seizure disorder and was on Phenytoin for the last eighteen (18) months and which was continued till ten (10) weeks of pregnancy. Once pregnancy was confirmed, it was switched over to Carbamazepine. She was seizures free throughout the pregnancy.

The live born $3.6 \mathrm{~kg}$ male neonate was noted to have webbed-short neck with slanted palpebral fissures, a depressed nasal bridge, coarse profuse scalp hair, short nose with bowed upper lip and ocular hypertelorism (Fig. 1).The baby also had widely spaced small nipple with absent areola along with hirisutism. Further examination revealed a cleft palate, hypoplasia of nails (Fig. 2), hypoplasia of distal phalanges, abnormal palmar crease, and a single umbilical artery, depressed skin on sacral region, hypospadias and cryptorchidism. As suggested from the maternal history and the features of the newborn, the diagnosis of Fetal Hydantoin Syndrome was made. However, baby went into respiratory distress due to moderate birth asphyxia and expired on the $3^{\text {rd }}$ day of life.

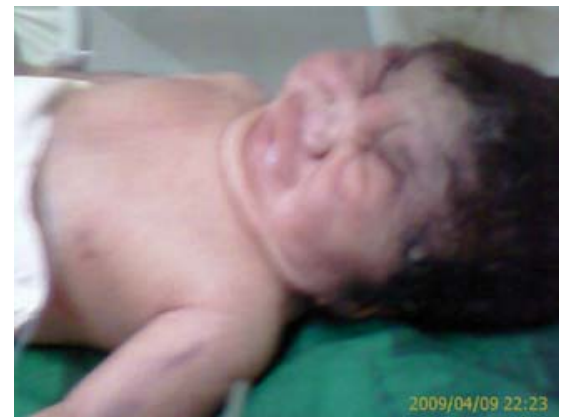

Fig. 1: Dysmorphic facies in Fetal Hydantoin Syndrome

\section{Discussion}

Phenytoin, formerly called diphenylhydantoin, was first discovered in 1938'. It is an effective anti epileptic drug used in suppressing tonic-clonic and partial seizures in the adult age group. It is preferred to other anticonvulsant drugs due to its well defined therapeutic level in serum than other anticonvulsants, easier withdrawal, no addiction liability and no drug antagonism. 


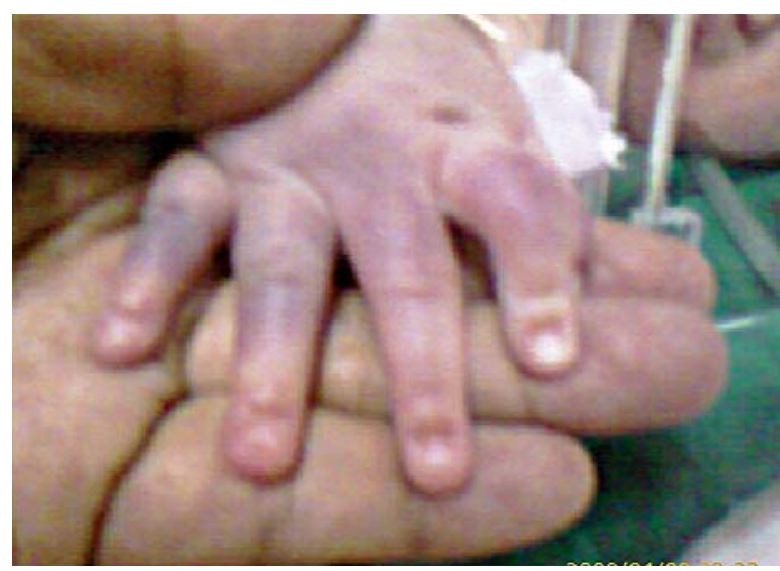

Fig. 2: Hypoplastic nails in Fetal Hydantoin Syndrome.

Its teratogenic effects were first recognized in $1968^{2}$. Phenytoin may induce folic acid deficiency in the epileptic patient by impairing $\mathrm{Gl}$ absorption or by increasing hepatic metabolism ${ }^{3,4,5}$. Therefore, the risk for having a baby with a spinal abnormality is increased. Some reports have shown that phenytoin is a transplacental carcinogen ${ }^{6}$. Tumors were reported to occur after in utero exposure to phenytoin in a few cases. Drug is thought to deplete already low levels of fetal vitamin $\mathrm{K}$ therefore suppressing the vitamin $\mathrm{K}$ dependent coagulation factors. Taking oral vitamin $\mathrm{K}$ during last 2 months of pregnancy and the administration of $\mathrm{Vit} \mathrm{K}$ to the newborn is proposed for the risk of hemorrhagic incidents ${ }^{7}$. In a study conducted from 1985 to 1992,332 newborns exposed to phenytoin during the $1^{\text {st }}$ trimester were studies. A total of $15(4.5 \%)$ had major birth defects, including cardiovascular, spina bifida and hypospadias ${ }^{7}$. It is also known to cause cleft lip and cleft palate ${ }^{7}$.

Fetal Hydantoin Syndrome is characterized by broad nasal bridge, wide anterior fontanelle, low hairline, broad alveolar ridge, short neck, hypertelorism, microcephaly, cleft lip/palate, low set ears, epicanthal folds, ptosis, coloboma and coarse scalp hair. The limbs may have small or absent nails, hypoplasia of distal phalanges, altered palmar crease, digital thumb and dislocated hip ${ }^{1}$. Mild to moderate growth deficiency, usually prenatal in onset is usually observed in children with the syndrome. Occasional borderline to mild mental deficiency is observed. However performance in childhood is usually better than that predicted in infancy'. Occasional cardiovascular abnormalities such as aortic valvular stenosis, coarctation of aorta, PDA, and septal defects and $\mathrm{Gl}$ abnormalities such as pyloric stenosis, duodenal atresia and anal atresia as well as small widely space nipples, umbilical and inguinal hernia have been reported $^{1}$. Risks of delivering a child with congenital

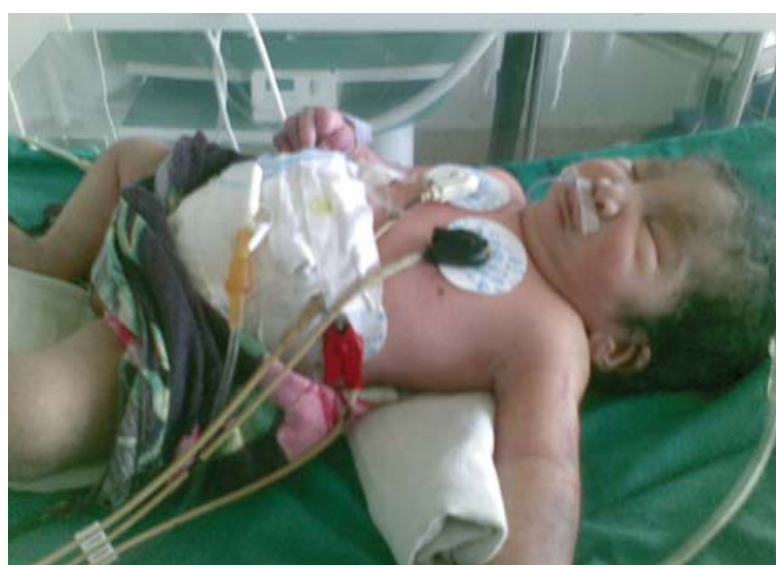

Fig. 3: Fetal Hydantoin Syndrome

defects are 2-3 times greater for women taking dilantin than for the general population. Increased risk could be caused by epilepsy, the drugs, or a combination of the two. It is thought that the drugs are the causative factor. Risks of child having full syndrome is about $10 \%$ and the risk for having some of the effects of the disorder is an additional $33 \%^{9 \cdot 10}$. However, a pregnant woman not taking Phenytoin or other antiepileptics have an increased risk of seizures during the period and risk fetal hypoxia.

\section{Conclusion}

Due to the documented pattern of malformations with the use of hydantoin, it is evident that the drug be discontinued when possible. But due to lack of evidence that other anti convulsants are any safer in pregnancy, it is important that the women of reproductive age group on hydantoin or any other anti convulsants be properly counseled about the risks of continuing the drug during pregnancy and the risk benefit be analyzed before any decision is taken.

\section{References}

1. Jones KL. Smith's recognizable patterns of human malformations. 5th edition. W.B. Saunders Company: Philadelphia. 1997; 495-499.

2. Biale $Y$, Lewenthal $H$. Effect of folic acid supplementation on congenital malformation due to anticonvulsive drugs. EUR J Obstet Report Biol 1984; 18:211-6

3. Hansen JW, Myranthopoulos JC, Sedgewick Harvey MA, Smith DW. Risks to the offspring of women treated with hydantoin anticonvulsants, with emphasis on the fetal hydantoin syndrome. $J$ Pediatr 1976; 89; 662-8 
4. Pritchard JA, Scott DE, Whalley PJ. Maternal folate deficiency and pregnancy wastage, IV. Effects of folic acid supplementation, anticonvulsants, and oral contraceptives, Am J Obstet Gynecol 1971; 109:341-6.

5. Hilesmaa VK, Teromo K, Granastom ML, Brady $\mathrm{AH}$. Serum folate concentration during pregnancy in women with epilepsy relation to antiepileptic drug concentration, number of seizures, and fetal outcome. Br Med J 1983; 287: 577-9

6. Mycek MJ, Harvey RA, Champe, PC, editors. Lippincot's Illustrated Reviews: Pharmacology, Drugs used to treat epilepsy 1997; p. 143-150
7. Briggs GG, Freeman RK, Yaffe SJ. Drugs in Pregnancy and Lactation. 5th edition. Baltimore: Williams \& Wilkins, 1475-1487

8. Lane PA, Hathaway WE. Vit K in infancy. J Pediatr 1985;106:351-9

9. Gaily E, Kantola-Sorsa, Granstrom M-L. Intelligence of children of epileptic mothers. J Pediatr 1988; 13:677-84.

10. Speidel BD, Meadow SR. Maternal epilepsy and abnormalities of the fetus and newborn. Lancet 1972; 2: 839. 